\title{
Corpus
}

Archivos virtuales de la alteridad americana

Vol 3, No 2 | 2013

Julio / Diciembre 2013

\section{La larga celebración de la conquista del desierto}

1979. The long celebration of the Conquest of the Desert

Javier A. Trímboli

\section{(2) OpenEdition}

Journals

Édition électronique

URL : http://journals.openedition.org/corpusarchivos/568

DOI : $10.4000 /$ corpusarchivos.568

ISSN : 1853-8037

Éditeur

Diego Escolar

Référence électronique

Javier A. Trímboli, « 1979. La larga celebración de la conquista del desierto », Corpus [En línea], Vol 3,

No 2 | 2013, Publicado el 20 diciembre 2013, consultado el 19 abril 2019. URL : http://

journals.openedition.org/corpusarchivos/568; DOI : 10.4000/corpusarchivos.568

Ce document a été généré automatiquement le 19 avril 2019.

Licencia Creative Commons: Atribución-NoComercial 2.5 Argentina (CC BY-NC 2.5 AR) 


\section{La larga celebración de la conquista del desierto}

1979. The long celebration of the Conquest of the Desert

Javier A. Trímboli

\section{NOTE DE L'ÉDITEUR}

Fecha de recepción del original: 24/09/2013

Fecha de aceptación para publicación: 15/11/2013

Fuentes

Entusiasta adhesión popular en los actos evocativos realizados ayer. (1979, junio 12). La

Prensa

Convicción, 25 de mayo de 1979.

La empresa asumida es responsabilidad de todos. (1979, junio 12). La Nación.

Suplemento Especial Centenario de la Campaña del Desierto. (1979, junio 11). Clarín

La conquista del desierto. (1979, junio 11). Clarín.

Todo es Historia. Edición Especial: Campaña del desierto: una epopeya argentina. (1979)

(tomo114).

La Nación, 12 de junio de 1979.

La Prensa, 12 de junio de 1979.

Más allá de las conclusiones a las que se arribe, la discusión sobre el genocidio a propósito de la llamada conquista del desierto invita a hacer un ejercicio que había quedado decididamente postergado: la puesta en trama de las ofensivas desplegadas por el Estado -o por las fuerzas que bregaban por su conformación- contra las clases populares o un sector de ellas. Una vez desmoronada la última dictadura militar, no era descabellado suponer que el accionar pasado del Estado y de las clases dominantes sería abordado de manera sostenida por una mirada con mejores reflejos críticos y cargada de nuevas sospechas. Sin embargo, esto no fue así. El temor al anacronismo, que todavía hoy se 
blande como amonestación, sólo en cierta forma explica la dilación. Sin entrar de lleno en esa discusión, vale, no obstante, advertir sobre el equívoco que conlleva suponer que el ejercicio del terror de la última dictadura, tan sistemático como incontrolable, no tuvo escuela y fue por eso una excepción en nuestra historia. Este artículo se abocará a la celebración del centenario de la conquista del desierto que tuvo lugar en 1979 y, en este sentido, sólo de manera oblicua se aproximará a la cuestión. Sin embargo, en diálogo con lo señalado por Julio Vezub en esta revista (2011), al reparar en una coyuntura en que se anudaron de manera poderosa un conjunto de intervenciones políticas, periodísticas e historiográficas, en las que pasado y presente se citaron -el tema del artículo-, consideramos que puede ser un aporte al problema planteado. Porque el juego de espejos que en 1979 se montó devolvía imágenes que, aunque no eran idénticas, se reconocían e incluso alcanzaron a sobrevivir durante los años de la democracia.

2 El acto central se llevó a cabo el lunes 11 de junio en la ciudad de Neuquén, en coincidencia con la llegada, cien años atrás, del ministro de Guerra Julio A. Roca y del ejército expedicionario a la confluencia de los ríos Limay y Neuquén. La comitiva oficial era numerosa. Además del presidente Videla, se encontraban presentes el ministro del Interior Albano Harguindeguy, su par de Trabajo Llamil Reston, el jefe del Estado Mayor del Ejército, Suárez Mason, el gobernador de la provincia anfitriona, Domingo Trimarco y el director de Gendarmería Nacional, Antonio Domingo Bussi. Todos generales. Entre los doctores: el ministro de Economía Alfredo Martínez de Hoz y el de Cultura y Educación Juan Llerena Amadeo. Con autoridades eclesiásticas, todos en el palco ante un auditorio en el que también hay soldados y civiles. Según La Nación son dos los contingentes que sobresalen: el de los caciques y tribus indígenas que representan a sus antepasados que colaboraron con la expedición y el casi centenar de jinetes que habían partido a comienzos de mayo desde Bahía Blanca con el propósito de reproducir el desplazamiento del ejército. También desfilan más de mil niños de escuelas de la región. Videla se hallaba en la Patagonia desde días antes: el sábado, en Comodoro Rivadavia, había participado del "acto de bendición de la nueva catedral"; el domingo, en San Martín de los Andes, y subraya la misma crónica que, acompañado de su mujer, se movilizó en un auto sin escolta. El vehículo militar que el lunes 11 de junio lo trasladó hasta el palco fue aclamado por la multitud. El periódico La Prensa interpreta:

"No hubo temor por la cercanía del pueblo. Nadie molestó a los manifestantes que tampoco daban motivo para un control excesivo (...) Fue la prueba de una identificación honesta y desinteresada hacia los motivos de esa evocación. Por esta causa creemos que fue un hecho significativo y digno de ser destacado, y quizás habrán pensado aquellos que tienen hoy la responsabilidad política del país, que algo está cambiando en el comportamiento generalizado de los argentinos y que los frutos de una constante prédica están comenzando a advertirse" (1979, junio 12).

3 En claro contraste, el acto compartirá la primera plana de los principales diarios del país con los enfrentamientos cada vez más álgidos que en Nicaragua se sucedían entre guerrilleros y el gobierno de Somoza.

4 Las palabras del presidente Videla evitaron casi toda desmesura, cosa que vale señalar luego de que el derrumbe de esa experiencia política -la del Proceso de Reorganización pero en particular la de ese momento- hizo que prefiriéramos creer que el cuchillo siempre estuvo entre los dientes. Más que con la figura de Roca, identificarse con "una gloriosa y trascendente gesta de todos los argentinos" fue de especial interés para la dictadura. Una epopeya afirmativa de la nacionalidad y de la soberanía sobre tierras hasta "entonces señoreadas por la soledad y el desamparo". Dicho esto en momentos en que el 
conflicto limítrofe con Chile, después de la escalada de fines de 1978, apenas estaba acallado. Hablar de ese "episodio mayor de la historia nacional" conducía de inmediato a hacer resaltar el papel de las Fuerzas Armadas que, además, en esa ocasión habían sido bien secundadas por otros sectores sociales -maestros, colonos, sacerdotes, científicos-, en el desafío de llevar el progreso a la Patagonia. Porque las palabras de Videla disparadas durante la conmemoración también hacen el elogio de la civilización, de la República y de las virtudes del pueblo argentino. Algo menos se nombra a los vencidos, como si de la derrota naturalmente se desprendiera su oscurecimiento. En este punto, el discurso de Videla nuevamente sobresale, por su tono medido y hasta honorable: los nombra "malón", habla de ellos como una "noble estirpe" y evoca al "indiecito", a su "beatitud", "virtud y pureza", en evidente, pero implícita, referencia a Ceferino Namuncurá. En otro discurso oficial, el ministro Harguindeguy, en el congreso de historia de General Roca, dirá "indio extranjero". Entre una y otra denominación, pero más cerca de esta última, se delineará su silueta. De una o de otra forma, una bruma espesa cae sobre ellos en el texto mayor que, con aportes e inflexiones de una pluma y de otra -militares y civiles-, se va a ir hilvanando.

5 Sin dudas, la dictadura gusta de ubicarse en continuidad con el acontecimiento celebrado. No obstante -y para mejor percibir la singularidad de lo que será una breve coyuntura-, una semana atrás, la participación de Videla en el acto del Día del Periodista, y en reconocimiento de la labor de Mariano Moreno, nos advierte sobre la pretensión de no quedar desasidos de la historia nacional escrita por el liberalismo. Aunque, claro está, ahora aún más cruzado que en las décadas previas por incrustaciones del catolicismo, así la advocación a "su Santísima Madre, Nuestra Señora de Luján, patrona del pueblo argentino" con que Videla cierra sus palabras. Difícil encontrar algo con este último tono en Convicción, diario que sale a la calle desde agosto de 1978 y, era un secreto a voces, respondía a las directivas de Massera que, retirado del almirantazgo, proyectaba su lanzamiento político. En la editorial del 25 de mayo, no hay mención al centenario de la ocupación militar del Río Negro en Choele Choel, sino enfáticamente a Moreno como figura principal de la revolución que aún no ha llegado al término que él mismo le había imaginado. "Los argentinos mantenemos para con ella la deuda de completarla, organizando de una buena vez una democracia auténtica, representativa y federal, moderna y estable. En eso estamos". Permítasenos la acentuación: hasta el punto de decir cosas como éstas llegaba la voluntad de seguir adscriptos al liberalismo. De todas formas, que la preferencia por Roca y su empresa no fuera excluyente no alcanza a explicar por qué quedó tan postergada esta conmemoración, la más importante que se emprendió durante esos años y en la que la efusión historicista, por ejemplo, empujó a la Policía Federal a publicar, con el título Cuestión de Indios, entre otros, el libro de Santiago Arcos. En las palabras preliminares, el Jefe de esa fuerza, General de Brigada Juan Bautista Sasiaiñ -también presente en el palco del acto principal- indica que la empresa fue posible por la buena disposición de la Biblioteca del Jockey Club. Muy pocas huellas hay en los libros sobre el período de la celebración, de las alianzas que le dieron densidad.

6 Por fuera de lo impulsado por el poder ejecutivo, hay una iniciativa que se destaca. Clarín, junto con su edición del lunes 11 de junio -el día del acto en Neuquén-, publica un suplemento especial dedicado al tema. No hay improvisación en esta intervención que hace más de un mes se anuncia y allí, tal como lo señala Marcelo Valko, halla un cómodo lugar un anuncio celebratorio de la Sociedad Rural. A página entera recuerda el servicio prestado por la entidad cuando era presidida por José Martínez de Hoz y el ministro de 
guerra solicitó su colaboración. Mil quinientos caballos puestos a disposición del gobierno nacional para hacer avanzar la frontera. $Y$ remata:

“También hoy como ayer y como será siempre 'Cultivar el suelo es servir a la Patria

'. Como queda demostrado en ese episodio vivido en el siglo pasado, desde 1866 la

Sociedad Rural Argentina está consustanciada con la Patria y los productores

argentinos" (1979, junio 12).

7 Pero el problema que el suplemento presenta excede la complicidad entre esta empresa periodística y la dictadura. También la de la Sociedad Rural. Porque no pasa desapercibida la distancia entre sus 56 páginas y las sólo 6 del suplemento de Cultura de La Nación. Pero, más aún, el hecho de que las principales firmas en el diario de los Mitre son casi en su totalidad de militares, que hacen que lo escrito resuene a la misma dictadura: los generales retirados Tomás A. Sánchez de Bustamante y Gustavo Martínez Zuviría, el contraalmirante (R) Laurio H. Destéfani. Y en Clarín todo se expande, porque los textos con firma castrense son los menos y se pierden entre los de colaboradores que, o bien ya tenían una trayectoria dilatada en la cultura -y en franjas que no eran las de la derecha arquetípica y rancia-, o que la tendrían prontamente. Así: Raúl Larra, Miguel Ángel Scenna, Félix Luna, Ezequiel Gallo, Gustavo Ferrari, Roberto Cortes Conde, Marcelo Monserrat, Rita Segato. Por un momento, a los casi 500.000 lectores diarios de Clarín -una cifra en pleno ascenso (Sivak, 2013, p. 314)- lo ominoso se les olvida. De seguro en 1979, quizás incluso en una lectura actual.

Los artículos del suplemento especial pretenden abarcar el acontecimiento por entero, desde el papel de la Armada hasta las imágenes que el cine le dedicó, desde el significado económico para la Argentina en tren de modernización hasta la situación presente de la población indígena de Neuquén. No es sorpresa que todo tienda a lo homogéneo. Sobresalen algunos nombres propios entre los expedicionarios pero, finalmente, lo que se destaca es la vastedad de la empresa colectiva. Aunque con menos énfasis que en los discursos oficiales, se trata de un episodio de la épica nacional, algo más de una obra de progreso. Mientras que en La Nación todo se sostiene en la voluntad y decisión de una comunidad política de larga data -ya que la continuidad con España es central-, artículos del suplemento que se alejan de la mera epopeya, como los de Gallo y Cortés Conde, invitan a que se aprecie lo que tuvo de necesidad desprendida de las leyes de la economía. Por lo tanto, aplacada la política y el momento de la fuerza, las variables del desarrollo y la evolución sostienen la normalidad de la situación. No hay desmanes, ni siquiera de esos que se acostumbraba a decir que eran el precio de la nacionalidad. Lugones es citado por el general Ramón J. Camps, en una de las tres notas que publica en La Prensa en esos días, y queda estacionado a su derecha. Desdramatiza Cortés Conde en "Puesta en valor de las tierras" al referirse a los vencidos: "Poblaciones nómadas que no habían alcanzado el grado de desarrollo de las del noroeste y no habían logrado integrarse a la comunidad".

9 Si no con más precisión que en los discursos oficiales, aquél contra el que se combatió despunta con un atributo de signo negativo, su vínculo con Chile. El artículo que abre el suplemento cultural de La Nación, con la firma de Enrique de Gandia, enfrenta al indio chileno contra la Argentina, desde el siglo XVI hasta 1879. En Clarín, el análisis geopolítico y las adjetivaciones más triviales se entrelazan. Ferrari:

"Mal podía nuestro país asumir posturas firmes en el exterior, con el humo y la sangre de los malones a retaguardia, con los salvajes que desafiaban al Gobierno Nacional y aprovechaban los conflictos internacionales para redoblar sus exigencias de acuerdo a una fría y astuta política extorsiva" (1979, junio 11). 
10 No hay comparación alguna con el "subversivo", el derrotado en la ofensiva que se sostiene en 1979; solo la forma en que se los recorta, esa combinación de animosidad, desprecio y vaguedad, sugiere la relación. Olga Fernández de Latour de Botas, en la nota que cierra el suplemento, señala que por su incapacidad para evolucionar tecnológicamente, los indios constituían una cultura "destinada a desaparecer". El gaucho había sido el principal damnificado por su agresivo merodear, por lo tanto "el abrir camino para la paz y la seguridad del paisano gaucho fue la primera razón de justicia para la Campaña del Desierto". Se coloca a La vuelta de Martín Fierro en el centro del argumento y olímpicamente se ignora su primera parte.

"El 1 de junio el indio Platero me pegó un lanzazo en el costado izquierdo; le cacé la lanza y le devolví el obsequio con un confite de mi revólver, el que el imbécil en vez de tragarlo por la boca como es natural, se lo engulló por el ombligo; ahora he sabido que al llegar a Los Toldos murió. Esto me lo ha dicho un cautivo. Que el diablo lo conserve en una guampa..." (1979, mayo 25).

11 En un artículo en Convicción, Carlos A. Florit cita esta carta de Villegas. Su texto es un elogio del roquismo que busca evitar que se lo caracterice como un mero militarismo. Florit había sido el primer canciller de Frondizi y, al momento de su muerte, en 2010, fue recordado con razón por el intento de mantener relaciones con Cuba cuando ya se había descubierto que los barbudos guerrilleros no eran la versión caribeña de los fubistas. También por las críticas que dejó estampadas en un libro a las políticas contrainsurgentes, obsesionadas ya en los primeros años sesenta con la cruzada contra el comunismo. Un tipo avispado, digamos. Sin embargo, no hay sospecha alguna de que el fragmento transcripto pueda tener parentescos en su presente.

12 De todas formas, si hay algo que también le da carácter al suplemento de Clarín son los anuncios de adhesión a la conmemoración. Porque con la sola excepción de un par que promocionan la venta de autos de grandes marcas, todos los demás están dedicados al tema. Y aquí volvemos a la zona fundamental de entrecruzamiento, porque los oficiales son una buena cantidad -desde gobiernos de provincias hasta Fabricaciones Militares y ENTEL-, pero conviven en armonía con los de empresas privadas: La Campagnola, Alfajores Guaymallén, Loma Negra, los fabricantes argentinos de Coca Cola. En la búsqueda de la síntesis y el impacto, los anuncios hurgan en una misma cantera, entre el desierto, su conquista, la Nación, la gesta y su ejemplaridad. "Nos esperan otras campañas del desierto", vaticina Naya, una empresa de publicidad.

13 Aunque previsible, la sensación de que falta el aire ante un texto sin fisuras sólo se modera al detectar las marcaciones y fintas de algunos artículos. La primera está en la editorial del día, en el cuerpo principal del diario. El cuestionamiento no apunta al acontecimiento en sí, ya que no hay duda de que se celebra la epopeya que rescató miles de leguas al "reinado del salvaje" y que introdujo a la Argentina en el mundo moderno. La cuestión es el esfuerzo desaprovechado, porque no se comprendió que el paso siguiente a dar era la industrialización de la economía. La nota con que se inicia el suplemento y sirve como marco general va en el mismo sentido:

“Es así que para 1910, cuando se cerraba la frontera de tierras explotables y los prolegómenos de la Gran Guerra indicaban la necesidad insoslayable de la industrialización, en medio de la frívola celebración del Centenario, el programa del Ochenta, que había nacido con la Conquista, se convertía en el canto de cisne de un grupo vigoroso de argentinos". 
De vuelta Florit deja estampado su nombre, ya que en 1979 es un miembro prominente del frigerismo, aún a la cabeza de Clarín. En la editorial se usa la crítica como advertencia presente:

"Hoy, al cumplirse cien años de la gesta de Roca, no puede haber mejor homenaje a los hombres que hicieron la Conquista del Desierto que incorporar las regiones dispersas al mercado nacional y recuperar el tiempo perdido en el camino de la industrialización y el poblamiento de todo nuestro territorio" (1979, junio 11).

Como lo muestra Martín Sivak, el apoyo de Clarín y el frigerismo al proceso político en marcha desde 1976 sólo se vuelve reticente cuando se enfoca la política económica; por eso también el entusiasmo ante el desplazamiento de Martínez de Hoz, con el inicio de la presidencia de Viola en los primeros meses de 1981. Una fórmula similar, que distingue la hora política sin mácula de la económica, se traslada al pasado en celebración.

El señalamiento que hace Félix Luna en su artículo del suplemento tampoco ensombrece el acontecimiento conmemorado. A la vez que afirma que Roca fue quien "dio la última puntada a la urdimbre que cosió el Desierto a la integridad de la Nación", reiterará: "por favor, no lo idealicemos". La canonización en marcha pasa por alto que no supo manejarse siquiera un poco más allá de las limitantes ideológicas y políticas de la época, las del liberalismo. La nota es una más en el suplemento, pero Luna es la figura de mayor reconocimiento público entre quienes allí colaboran. Menos de un mes atrás se había estrenado La fiesta de todos, la película dirigida por Sergio Renán sobre el Mundial del `78, y el historiador era una de las figuras principales que le daban sentido cultural a ese suceso. De todas maneras, no es tanto la toma de distancia respecto del culto a Roca lo que hace desentonar a la nota, sino cierto desenfado. Recuerda también que eso era posible. "Aunque sólo sea por respeto a Roca, que hubiera mordido una de sus famosas sonrisas, llena de sarcasmo y desapego, si hubiera asistido a su canonización póstuma".

Al leer este suplemento nos gana la impresión de que la sociedad civil toma en él la palabra sin mayores restricciones. Las leves objeciones suman en este sentido. Si era sencillo sospechar del subrayado que hacían las crónicas del entusiasmo de la multitud en el acto, aquí el fondo unánime se confirma. Se podría decir que es la acción usual de la prensa, pero habría que añadir la particularidad del dispositivo Clarín y su fenomenal capacidad para oír a la opinión pública y también para hacerla hablar, para darle forma. Mucho más que revestido, el núcleo duro de la dictadura casi no se ve. No importa que estemos en esos años y que Martín Rodríguez (2011, p. 16) lo proponga como una posibilidad en relación con los de la transición democrática: Clarín pretende ser "el muro de contención del sentido común" y lo logra con no poca eficacia. Faltaría articular el sentido común con las clases. Y, por supuesto, en la particularidad de esa coyuntura que lo hacía tan maleable y que estaba dada por la finalización de la "guerra contra la subversión" declarada en 1978; la normalización institucional es el horizonte que postula el sector de las Fuerzas Armadas (FFAA) que es decisivo en el Poder Ejecutivo. En la mitad inferior de la tapa de La Nación del día posterior al acto, también se lee: "Videla: se quiere instaurar una democracia pluralista". Los altos índices de consenso que la dictadura cosecha después del Mundial se mantienen durante el año que nos interesa y un poco más. Las tensiones al interior de las FFAA no llegan a empañar esta situación, tampoco la inflación. Volviendo a las dos notas principales del día, tal como las cubre La Nación: mientras que el momento de la guerra impera en Nicaragua -con una foto que podría recordar lo que entre nosotros se había vivido-, en la Argentina se está cerca de la la ley y de la tranquilidad que aporta. 
Aunque envuelta en mortaja, la película que se estrenó en conmemoración de la conquista del desierto -por supuesto con apoyo oficial- también desliza objeciones que le valieron alguna amonestación. Porque en De cara al cielo, tal el título de esta película que dirige Enrique Dawi, además de subrayarse que la guerra no fue contra el indio, se reconoce algo del final de La Patagonia Rebelde: nuevamente un coronel del ejército, aunque esta vez al pie de la cordillera, termina descubriendo que todo su esfuerzo está yendo a parar a manos de los estancieros ingleses. Fortín Quieto fue la miniserie, la primera en color, dedicada al tema y transmitida por canal 9. Inhallable hoy, cuenta su guionista Cernadas Lamadrid que, aun cuando el proyecto fuera supervisado por el ejército, logró sumar a Fermín Chávez como asesor y así se le imprimió un sesgo revisionista. De cara al cielo también parece sobrevolada por esa influencia. En el suplemento de espectáculos de Clarín se la juzga con severidad, sobre todo por las inconsistencias del guión que parecen superponerse con las ideológicas. Convicción apunta hacia otro lado, porque si bien valora que esta película "se aleja de la grandilocuencia de otras incursiones del cine histórico nacional", cuestiona que no se haya animado a mostrar sucios a los personajes y con "todas las grandezas y debilidades de los hombres enfrentados a situaciones límites". Posiciones críticas resuenan en una nota de la revista Todo es Historia del mes de mayo, número dedicado por completo al tema, a través de la publicación de los textos ganadores del concurso convocado. La tapa presenta un pesebre realizado por la hija del general Ignacio H. Fotheringham -inspirado en el célebre cuadro del Blanes- y que fuera expuesto en la Feria del Libro de ese año. "A la Universidad. Advocación: Año Internacional del Niño y Centenario del Inicio de la Campaña al Desierto". Con el ánimo monocorde de homenaje contrasta el artículo de Emilio J. Corbière, "Adolfo Alsina: integrar al indio sin genocidio". Es una semblanza en extremo favorable del primer ministro de Guerra de Avellaneda y de su política, pero lo que interesa es que se trata de una hendidura en el texto mayor y que por fin involucra al acontecimiento mismo. La palabra genocidio queda escrita, aunque más por lo que pudo evitarse que por lo efectivamente sucedido.

"Pero si muchas de las ideas estratégicas de Alsina hoy pueden considerarse erróneas, y algunas lo fueron, el espíritu de su planteo, basado en la progresiva colonización de la Patagonia y del Sur argentino, sin el genocidio indígena, constituyeron un ideario progresista para la época" (1979, p.63).

Atada a la suerte pública de Félix Luna, aunque unos pasos atrás suyo, la revista Todo es Historia gozaba -y pocas veces la expresión será más dudosa- de no poca visibilidad. Así y todo, la nota de Corbière está en sus bordes. De vuelta en el suplemento, Rita Segato nos hace recordar que hubo un 19 de febrero en ese año -un día como cualquier otro- en el que llegó a Viedma en compañía de una colega para internarse en el sur de la provincia de Río Negro. ¿El objetivo? La búsqueda de "la música actualmente ejecutada por las comunidades araucanas o mapuches que aún subsisten en la región". Si hay un obstáculo a vencer es "el influjo de los vicios occidentales de pensamiento" que tendería a restarle relevancia a ese material. Observa transformaciones mayores que se dan la mano con la expansión de las sectas protestantes que interpelan con su mensaje las viejas prácticas religiosas. En una línea de este artículo, que es uno de los largos, se deja escrito "represión ejercida por el Estado" -sin fecha ni contexto-, para entender la postergación de esas prácticas y el debilitamiento del poder de los caciques. Luce un poco más oculto el señalamiento porque de inmediato se hace alusión a otros factores, pero ahí queda y lo leemos. que disonaron con el texto mayor de la celebración. Si no las señalamos antes fue porque 
es alevosa la diferencia en cómo fueron recogidas por la prensa. Una plegaria pronunciada por el padre Juan Sebastián, canciller del obispado local. En La Nación, además de nombrarlo de esa forma, se reproducen párrafos de la misma:

"te pedimos, Señor, con todas nuestras fuerzas, que nunca más los argentinos derramen su sangre con enfrentamientos fratricidas. (...) Señor, si te hemos fallado en el pasado, hoy, ante tu presencia y la de tu pueblo, en esta plaza levantada como recuerdo del acontecimiento histórico que nos congrega y ante estas banderas argentinas, prometemos poner remedio a los errores, romper las diferencias raciales, promover a los marginados (...)" (1979, junio 12).

La crónica de Clarín ni siquiera menciona la presencia en el palco de este religioso y La Prensa reproduce por completo la plegaria, en la misma edición en que se publica una de las tres notas de Camps. Se lee entonces que el pedido de perdón incluye una caracterización más explícita de lo sucedido: "por habernos enfrentado los argentinos, utilizando la violencia anticristiana, el secuestro, el asesinato, la tortura, el odio, ignorando el mensaje de amor y de perdón; por haber marginado en estos cien años a los nativos de estas tierras" (7). Quizás no faltaron quienes vislumbraron en esta oración la crítica -ipor eso su ausencia en Clarín?-; el mismo padre, Juan San Sebastián, años después va a contar la molestia que trajo entre las autoridades militares, esa participación suya (San Sebastián, 1997). Un documento con un tono un poco más crítico había sido elaborado por el Presbiterio que tenía a Jaime de Nevares a la cabeza; de una decisión conjunta entre el obispo y los sacerdotes surgieron la aceptación de participar en el acto oficial y de hacerlo con esas palabras. Ahora bien, las alarmas no se encienden mucho más; el texto mayor de celebración de la conquista, que sale a relucir en 1979 y tiene al suplemento de Clarín en su centro, se apoya tan sólidamente en lo que la cultura argentina venía sosteniendo sobre este acontecimiento -ya que tampoco el revisionismo, en sus coordenadas más generales, lo había tenido como blanco-, es tanta la continuidad $y$, por lo tanto, la unanimidad reforzada, que las alarmas no tenían por qué encenderse.

22 No obstante no contar con la salvaguardia religiosa -tampoco con su peculiar forma de aportar a la bruma general, dirán quienes no quieran ver objeción en la plegaria-, en el Congreso Nacional de Historia de la Conquista del Desierto, celebrado en General Roca durante cuatro días del mes noviembre, se hizo lugar una ponencia como la de Rodolfo Casamiquela. Aunque el Congreso lo presidiera el ministro Albano Harguindeguy y el conjunto de escritos se publicara en cuatro tomos al año siguiente, su publicidad -quizás también el riesgo- fue muy otra que la de la plegaria. El señalamiento principal indica que la política de exterminio de la campaña de Roca se sostuvo en un empobrecimiento del conocimiento sobre el mundo indígena, que pasó del obligado plural de la época de Rosas al singular "indio". Y el empobrecimiento fue la negación de la política. En este mismo sentido, y teniendo como blanco uno de los motivos que el texto mayor repite, agrega respecto de Calfucurá y los suyos: “(...) mal se los puede calificar de chilenos... por ser Araucanos! Eran indígenas de la cordillera y no tenían otra patria que ella" (Casamiquela, 1980, p.146, tomo 1). Evidentemente tanto la coyuntura como la fuerza del texto mayor, habilitaba a que Casamiquela pudiera decir esto $\mathrm{y}$, a la vez, mostrarse complacido, como lo hace, por los avances que el Congreso está consolidando en el conocimiento etnográfico; sin que una cosa pareciera contradictoria con la otra.

23 En este Congreso aparecen las posiciones con las que se pretende discutir. Porque lo que hasta aquí prevalecía era la impresión de que se estaba al margen de toda conversación que no fuera enteramente amistosa. Escribe el coronel (R) Juan Carlos Walther en el suplemento que "estas simples líneas no encierran ningún ánimo ni idea de polémica", y 
la afirmación resume el espíritu dominante. La intervención de Harguindeguy, abriendo las jornadas, hace un reclamo todavía demasiado general: "Los argentinos, ingratamente, no conocemos a fondo los hechos que conformaron la conquista del desierto, ni la trascendencia que tuvo para el crecimiento del país, ni el aprovechamiento que de ella hizo la llamada generación del 80". En el discurso inaugural, el presidente de la Academia Nacional de la Historia, Enrique Barba, se refiere a un tiempo borroso que sin dudas no había quién no reconociera, en el que la historia había sido "intencionada y maliciosamente escrita" y en el que "una literatura desquiciadora (...) había arrumbado como nefanda la de los grandes maestros". La escena del Congreso, con el papel central de la Academia, era la de la recuperación del "texto" y la "lección" por encima del "panfleto" y la "arenga". Por eso, en la introducción del libro se añade:

"Cuando echo una mirada al pasado más o menos inmediato y advierto la desorientación que en aquel entonces dominaba a la juventud estudiosa que había llegado al extravío y observo en este momento la sana y nerviosa inquietud de los jóvenes llegados desde todos los ángulos de la República, ansiosos de saber, de acercarse a los que con libérrima elección consideran sus maestros mostrando su inocultable simpatía a la Academia, no puedo menos que pensar que nuestra Casa ha obtenido una significativa victoria en su acción magistral" (Barba, 1980, p.10).

Sin esa estridencia que parece a destiempo, también en el texto de Félix Luna en el suplemento de Clarín se lee con quién se busca discutir, pero siempre a propósito de Roca. Señala que su equívoca canonización es obra que le corresponde "a la izquierda nacional y al liberalismo tradicional que se aliaron curiosamente" con este propósito. De seguro que habría que hacerle lugar a los matices pero, en este punto, Luna llama a las cosas por su nombre. Si por fin nos movemos un año, a noviembre de 1980 -con otro centenario a cuestas pero en una coyuntura que se sostiene-, nos encontramos con que la respuesta que brinda Tulio Halperin Donghi, en el cuestionario que le acerca la revista Punto de Vista en su número 10, también apunta a esas dos líneas historiográficas de vasta influencia que se le ocurren al fin desplazadas. Pregunta: "El año pasado se conmemoró ampliamente el centenario de la Conquista del desierto y éste el acceso de Roca al poder. ¿Qué puede decirnos respecto de estos dos acontecimientos?" Respuesta:

"Esas conmemoraciones -dejando de lado el tono triunfalista y macizamente acrítico que la celebración de las efemérides imponen y la particular hora argentina en que ellas se dan no pueden sino acentuar- marcan un desplazamiento del núcleo de temas y problemas propuestos a la atención colectiva, que los acerca más a temas y problemas históricos reales. Se trata de la implantación del estado en todo el territorio y su consolidación por la afirmación -como decía el primer usufructuario de ella- del Imperium, dos cosas cuya importancia luego de décadas de debatir entre 'líneas históricas' alternativas que eran fruto de la brutal simplificación (cuando no de la mera invención) retrospectiva es bueno que se descubra" (Halperin Donghi, 1980, 4).

Las salvedades quedan claras y también que no alcanzan a deprimir el saldo positivo, en términos del conocimiento del pasado, que puso de relieve esa ocasión de centenarios: de la "brutal simplificación" a "temas y problemas históricos reales". La unanimidad de la "particular hora argentina", en relación con la perspectiva apropiada para enfocar lo sucedido cien años atrás, tiene incluso la fuerza para soportar y sobrellevar el cuestionamiento a la dictadura. La normalidad despunta también para la historiografía. Al mismo tiempo se postula que ya no hay contraste entre un Estado "vigoroso y ominipresente" y una sociedad de rasgos "indefinidos", porque la del presente es "todo menos desdibujada". 
Vale atender a este parecer de Halperin, aunque convendría recordar que "Una nación para el desierto argentino" -la larga introducción a Proyecto y construcción de una Nación (Argentina, 1844-1880)-, publicada en 1980, es una intervención inscripta en las limitantes de la coyuntura, también en su fecundidad: "En 1879 fue conquistado el territorio indio; esa presencia que había acompañado la entera historia española e independiente de las comarcas platenses se desvanecía por fin". Es una de las pocas oraciones, sólo hay otra más, donde el asunto se nombra. Tanto es lo que se acumula y expresa en la obra de Halperin, también en esta introducción, que sería ímproba la tarea de señalar lo mucho que la diferencia de las intervenciones que nos han interesado. Se podría argumentar, a su vez, que "Una nación para el desierto argentino" trata del dificultoso proceso de formación del Estado Nacional y que sólo en este sentido le da relieve a Roca. También que el tratar de historia política y de las ideas es lo que explica que queden afuera los indios. Pero en verdad éste y no otro es el asunto. Centenarios mediante, se puede narrar el proceso de conformación del estado con apenas una referencia de ocasión a los indígenas, dada su inexorable exterioridad a la vida política y de las ideas argentinas. Así, el problema que plantea esa oración, dominada por el uso del verbo "desvanecer", nos conecta de lleno con el texto mayor que estuvimos recorriendo.

27 Es altamente probable que Halperin no tuviera en mente estas celebraciones, ni mucho menos estas palabras por él escritas, cuando en La larga agonía de la Argentina peronista observa que en los años de la dictadura, como efecto del terror, "una nación cautiva se esforzaba por ver el mundo con los ojos de sus captores". Además, sería en vano preguntarse si el texto mayor de la celebración es también resultado de ese esfuerzo, porque el deslinde que se propone entre la nación y sus captores es por lo menos engañoso. Más interesante es otra observación: en la "opinión" se perpetuaba "una atonía facilitada además por los blandos contornos ideológicos que rodeaban a una represión sin precedentes" (p.106). Los "blandos contornos ideológicos" son los que quizás permitan entender que tantos se sintieran cómodos con ese texto y constituyen una pista certera sobre los motivos que en ese plano acompañan a las ofensivas incluso más violentas del Estado y las clases dominantes en nuestro país. Sin dudas, el suplemento de Clarín como corazón del texto que se fue hilvanando, es expresión de esos "blandos contornos ideológicos". El libro de Halperin también.

28 A mediados de 1981, la larga introducción a Proyecto y construcción de una Nación es reseñada extensamente en Punto de Vista por Luis Alberto Romero. Es un poco más que una celebración, como si se hubiera hallado el tono y la perspectiva necesarios. Señala Romero que en esas páginas hay una "deliberada elusión de una definición precisa de sus protagonistas" y la interpreta como "una actitud crítica ante sistemas de representación demasiado rígidos"; al mismo tiempo, hace contrastar la "preocupación por plantear los problemas en términos de la época" con "el anacronismo" de las "versiones ideologizadas" (pp. 30 y 31). Sin sospechar ningún problema, añade que "muchas de las opiniones de Halperin sobre la Argentina criolla parecen derivarse directamente de Paz, de Echeverría, de Alberdi a veces, y sobre todo del admirado y admirable Sarmiento". El matiz -y "las infinitas gamas del gris"- contra el blanco y negro. Para concluir con resonancia política: "Mensaje desencantado, sin duda, pero no necesariamente menos útil que el de quienes enfrentando la realidad con esquemas fáciles, terminan dando de cabeza contra ella" (p. 32). No cabe dudas de que se trata de la música que se escuchará en los claustros apenas unos años después y por mucho tiempo. Poco importa que, entre las 
"gamas del gris", los indios y más en general las clases populares se pierdan en la narración, enterrados.

En línea con esta argumentación, nuevamente en respuesta al cuestionario de Punto de Vista, se encuentra la preferencia de Halperin por la última novela de Manuel Puig -en la que ni el "protagonista", pero tampoco el autor, "entiende que le está sucediendo", en esa "Argentina tan difícil de reconocer"-, antes que por Cuerpo a Cuerpo de David Viñas donde el asunto es atacado "de frente". Si la revista que, como se sabe, va a hacer fundamental en la vida intelectual de la democracia, hasta ese momento había tenido a Viñas y a Halperin como dos de sus referentes relevantes, el contraste entre la reseña de Romero y la sucinta que Carlos Mangone le dedica en agosto de 1983 a Indios, ejércitos y fronteras, no deja dudas de cuál es la deriva abierta. Menos de una página y es la única colaboración de Mangone en la revista; es elogiosa y en el remate se propone una definición del "discurso del poder en la sociedad argentina": "una suerte de historicismo brutal (seductor de algún progresismo) que legitima 'lo que se impuso'" (Mangone, 1983). El libro de Viñas también tiene que ser puesto en relación con el texto mayor que nos interesa, pero como su más consistente revés.

Si la coyuntura que dio forma a la celebración del centenario de la conquista del desierto se desmoronó con tanto estrépito que quedó sepultada, "Una nación para el desierto argentino" fue uno de sus sobrevivientes. Su mismo título, tajante y transparente, es un destilado de ella. Otro: La Argentina del ochenta al centenario compilado por Gustavo Ferrari y Ezequiel Gallo. Por sus méritos, el libro de Halperin tuvo además la capacidad para desprenderse de ese contexto preciso y exportar ese humor ideológico a la vida intelectual de la democracia; así, la formación de más de una generación de historiadores en todo el país lo contó entre sus lecturas fundamentales. Problemático legado que, de no ser por su brillantez, se encontraría sin más entre los tantos otros que nos conducen a recordar cuánto de la democracia naciente estaba tomada desde muy cerca por lo que de improviso se había dejado atrás. Por el contrario, el libro que no encontró lugar en los extensos listados de bibliografía y que, por lo menos hasta el nuevo siglo, en poco o nada inspiró a la historiografía, fue Indios, ejércitos y fronteras. Vezub advierte sobre los cuestionamientos que se ganó por su supuesta simpleza. Algunos han quedado escritos, otros circularon en cantidad de pasillos y aulas durante estos años. Como en relación con la crítica literaria señala Jens Andermann: "de no haber sido tirada por la borda" la obra de Viñas hubiera podido alimentar otro programa para la historiografía, uno más acorde con la criticidad que se necesitaba luego de la experiencia vivida.

Cuando en un escrito publicado en 1987, Halperin Donghi refiera en una línea a los peones patagónicos contemporáneos a las matanzas de 1921 -a "los riesgos estadísticos" que afrontaban, para relativizar así la peligrosidad que acechaba a los hijos díscolos de las "clases respetables" durante la dictadura- (1987, p. 72), sin buscarlo advierte sobre la banalidad de una narración sobre el pasado que, aunque más no sea como punto ciego, deje espacio para la respiración y las zozobras de quienes por obra de las ofensivas desplegadas por el Estado -o en la normalidad- viven en estado de excepción. 


\section{BIBLIOGRAPHIE}

Andermann, J. (2013, julio). Una épica inconclusa. A Contracorriente, X (2). Disponible en: http:// www.ncsu.edu/acontracorriente

Barba, E. (1980). Introducción. En Congreso Nacional de Historia Sobre la Conquista del Desierto (pp.10). Tomo I. Buenos Aires.

Casamiquela, R. (1980). Los ingredientes étnico indígenas de la conquistas del desierto. En Congreso Nacional de Historia Sobre la Conquista del Desierto (pp.146). Tomo I. Buenos Aires.

Halperin Donghi, T. (1980). Cinco respuestas sobre historia argentina. Punto de Vista. 10, 4.

Halperin Donghi, T. (1980). Una nación para el desierto argentino. En Proyecto y construcción de una Nación (Argentina, 1844-1880 (p. XCV). Caracas: Biblioteca Ayacucho.

Halperin Donghi, T. (1994). La larga agonía de la Argentina peronista (p.106). Buenos Aires: Ariel.

Halperin Donghi, T. (1987). El presente transforma el pasado: el impacto del reciente terror en la imagen de la historia argentina. En AA.VV, Ficción y política. La narrativa argentina durante el proceso militar (p. 72). Alianza.

Mangone, C. (1983). Mínima. Punto de Vista. 18.

Rodríguez, M. (2011). De casa al mercado y del mercado a casa. Crisis. Abril/Mayo 2011.

Romero, L. A. (1981). Política, nación y Estado en la Argentina del siglo XIX. Punto de Vista. 11.

San Sebastián, Padre Juan (1997). Don Jaime de Nevares. Del Barrio Norte a la Patagonia, Buenos Aires, Centro Nueva Tierra.

Sivak, M. (2013). Clarín. El gran diario argentino. Una historia. Buenos Aires: Planeta.

Vezub, J. (2011). 1879-1979. Genocidio indígena, historiografía y dictadura. Corpus. Archivos virtuales de la alteridad americana, 1(2).

\section{RÉSUMÉS}

Este trabajo busca poner de relieve las intervenciones políticas, periodísticas e historiográficas que se sucedieron en el año 1979, a propósito de la conmemoración del centenario de la conquista del desierto. La dictadura militar adquiere protagonismo en esa evocación del pasado de tonos celebratorios, pero producciones como el suplemento especial publicado por Clarín muestran que de ningún modo fue exclusivo. En una coyuntura de importante consenso a favor del Proceso de Reorganización Nacional, con aportes de variado origen y de distintas firmas se va definiendo un texto mayor sobre el acontecimiento en cuestión. En él incluso hay lugar para diferencias y objeciones que, sin embargo, no terminan de desentonar con el humor ideológico compartido. A pesar de la descomposición de esa coyuntura, ocurrida con la guerra de Malvinas, algunos escritos fundamentales que ella alojó sobrevivirán a su derrumbe y harán su aporte para que la democracia y la nueva producción historiográfica conviva bien con esos tonos por lo menos conservadores. 
This article explores the political, journalistic and historiographical interventions made in 1979 on the occasion of the centenary of the so-called Conquest of the Desert. Though the 1976-1983 Argentine military dictatorship was clearly the protagonist among these celebratory evocations of the past, publications such as the special issue of the newspaper Clarín examined here indicate that it was not alone. Within a context of general support for the 'Process of National Reorganization', contributions from different sources and by different authors constructed a wider consensual narrative on the event in question. Even the differences and objections within that narrative never ultimately disrupted their shared ideological tone. Though the Malvinas War brought about the dismantling of this historical situation, some of the key texts written at the time would survive that collapse, eventually contributing to the way democracy and new historiographical production would co-exist with those -at the very least-conservative tones.

\section{INDEX}

Keywords : dictatorship, Conquest of the Desert, historiography, media

Palabras claves : dictadura, conquista del desierto, historiografía, medios de comunicación

\section{AUTEUR}

\section{JAVIER A. TRIIMBOLI}

Asesor historiográfico de la Televisión Pública, Argentina

Correo electrónico: javat66@gmail.com 